Document downloaded from:

http://hdl.handle.net/10251/89681

This paper must be cited as:

Ali, M.; Ramirez Hoyos, P.; Nasir, S.; Cervera Montesinos, J.; Mafe, S.; Ensinger, W. (2017).

Tetraalkylammonium Cations Conduction through a Single Nanofluidic

Diode: Experimental and Theoretical Studies. ELECTROCHIMICA ACTA. 250:302-308. doi:10.1016/j.electacta.2017.08.078

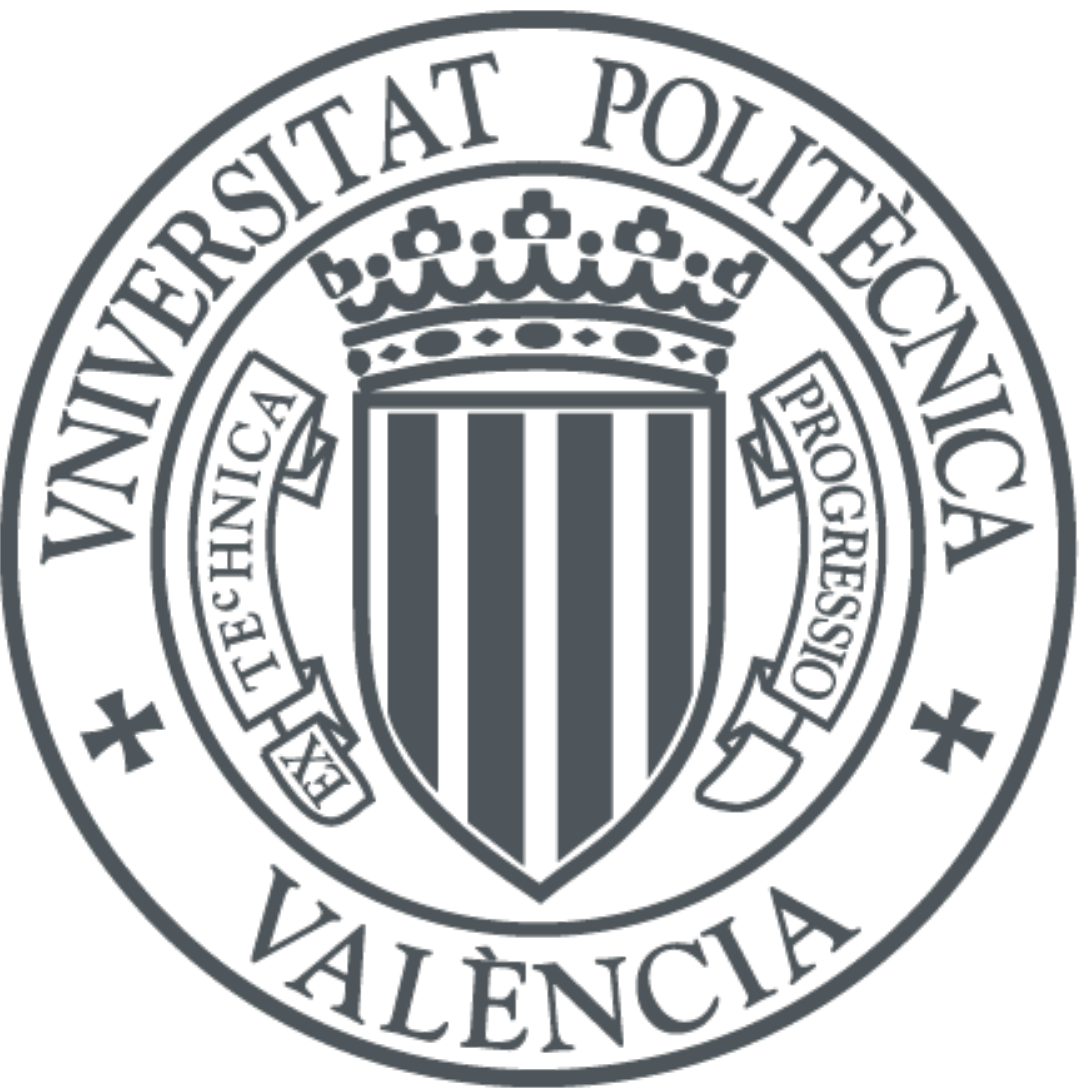

The final publication is available at

https://doi.org/10.1016/j.electacta.2017.08.078

Copyright

Additional Information 


\title{
Tetraalkylammonium Cations Conduction through a Single Nanofluidic Diode: Experimental and Theoretical Studies
}

\author{
Mubarak Ali, ${ }^{\mathrm{a}, \mathrm{b} *}$ Patricio Ramirez, ${ }^{\mathrm{c}}$ Saima Nasir, ${ }^{\mathrm{a}}$ Javier Cervera, ${ }^{\mathrm{d}}$ Salvador Mafe, ${ }^{\mathrm{d}}$ Wolfgang Ensinger ${ }^{\mathrm{a}}$ \\ ${ }^{a}$ Technische Universität Darmstadt, Fachbereich Material- u. Geowissenschaften, Fachgebiet Materialanalytik, \\ Alarich-Weiss-Str. 2, D-64287 Darmstadt, Germany \\ ${ }^{\boldsymbol{b}}$ GSI Helmholtzzentrum für Schwerionenforschung, Planckstr. 1, D-64291 Darmstadt, Germany \\ ${ }^{c}$ Departament de Física Aplicada, Universitat Politécnica de València, E-46022 València, Spain \\ ${ }^{d}$ Departament de Física de la Tierra i Termodinàmica, Universitat de València, E-46100 Burjassot, Spain.
}

\begin{abstract}
We describe experimentally and theoretically the concentration-dependent conduction of tetraalkylammonium $\left(\mathrm{TAA}^{+}\right)$cations through a nanofluidic diode fabricated in a polymer membrane via asymmetric track-etching techniques. This single-pore membrane exhibits current rectification characteristics because of the ionized carboxylate groups on the pore surface. We use aqueous solutions of potassium $\left(\mathrm{K}^{+}\right)$, ammonium $\left(\mathrm{A}^{+}\right)$, tetramethylammonium $\left(\mathrm{TMA}^{+}\right)$, tetraethylammonium $\left(\mathrm{TEA}^{+}\right)$, and tetrabutylammonium $\left(\mathrm{TBA}^{+}\right.$) ions with concentrations ranging from 50 to $500 \mathrm{mM}$ under acidic (pH 3.5) and physiological ( $\mathrm{pH}$ 6.5) conditions. Compared with the $\mathrm{K}^{+}$and $\mathrm{A}^{+}$ions, the $\mathrm{TMA}^{+}$, $\mathrm{TEA}^{+}$, and $\mathrm{TBA}^{+}$ ions show relatively low rectified ion currents because the cation hydrophobicity increases with the alkyl chain. At low concentrations and acidic conditions, an inversion in the current rectification characteristics is observed, which is attributed to the adsorption of the organic cations on the pore surfaces. The experimental results can be analyzed in terms of the Poisson-Nernst-Planck equations and the geometrical and electrical single pore characteristics for the different ions, $\mathrm{pH}$ values, and salt concentrations employed. This theoretical approach is qualitative and could be extended further to include a selfconsistent theoretical treatment of the ionic adsorption and surface charge equilibria.
\end{abstract}

Keywords: tetraalkyammonium cations; biomimetic nanopore; current rectification; nanofluidic diode; Nernst-Planck equation.

*Corresponding author: M.Ali@gsi.de 


\section{Introduction}

Biomimetic nanopores show ionic current rectification and permselectivity characteristics that can mimic some of the properties observed in biological ion channels [1] and offer new possibilities for electrochemical sensing [2-9]. To date, various routes have been proposed to fabricate synthetic nanopores in a variety of insulating solid-state materials [3-9]. The nanopore fabrication by ion track technology allows controlling the number and dimensions of the pores, from single to multipore membranes, the geometry (cylindrical, conical, and cigar-shaped pores), and the surface functionalization [8].

Ion current rectification phenomena can be observed in conically shaped nanopores because of the axial asymmetry of the ionized groups fixed on the pore surface $[2,10-14]$ and also in cylindrical nanopores with non-homogeneous fixed charge distributions [15-19]. In most studies, inorganic salts (e.g., $\mathrm{KCl}$ and $\mathrm{NaCl}$ ) in aqueous solutions have been used. Siwy and co-workers have considered the case of ionic liquids, aprotic solvents, and solid-state electrolytes [20-22]. Also, Yin et al. have studied transport phenomena at the nanoscale using organic solvents where the electrolyte ions adsorbed on the pore surface can cause charge inversion and current rectification [23]. We propose now to describe experimentally and theoretically the transport of organic cations through single conical pores.

Tetraalkylammonium $\left(\mathrm{TAA}^{+}\right)$cations have received much attention in analytical chemistry, electrochemistry, and biophysical chemistry [24-27]. In particular, the $\mathrm{TAA}^{+}$cations are potent blockers of several cation-selective ion channels $[1,27]$. In the case of $\mathrm{K}^{+}$-selective channels, the transient binding of ammonium cations to the channel can block the ion conduction pathway, preventing the entry of $\mathrm{K}^{+}$into the channel and leading to a reduction of the channel conductance [28-30]. Similarly, $\mathrm{Na}^{+}$and $\mathrm{Ca}^{2+}$-selective channels show significant current blocking by bulky 
organic and $\mathrm{TAA}^{+}$cations $[31,32] . \mathrm{TAA}^{+}$solutions have also been employed as supporting electrolytes in organic electrochemistry [33] as well as in DNA conformational and hybridization studies [34-37]. Recently, Kang and co-workers have discussed the advantages of using TAA instead of $\mathrm{KCl}$ electrolytes in the detection of DNA molecules translocated through a protein pore $[36,37]$. Thus, a comprehensive description of the ionic conduction properties of $\mathrm{TAA}^{+}$ions in confined geometries is timely.

We describe here the concentration-dependent conduction of different $\mathrm{TAA}^{+}$cations through a nanofluidic diode, comparing the results obtained with the usual $\mathrm{KCl}$ aqueous solution case. This diode is a single conical nanopore fabricated in a polymer membrane via asymmetric track-etching techniques [8]. Due to the ionized carboxylate groups on the pore surface, the nanopore exhibits current rectification. Aqueous solutions of ammonium $\left(\mathrm{A}^{+}\right)$, tetramethylammonium $\left(\mathrm{TMA}^{+}\right)$, tetraethylammonium $\left(\mathrm{TEA}^{+}\right)$, and tetrabutylammonium $\left(\mathrm{TBA}^{+}\right)$ are employed to characterize the effects of these bulky cations on the pore conductance and rectification at acidic $(\mathrm{pH}$ 3.5) and physiological $(\mathrm{pH}$ 6.5) conditions. In each case, the experimental results are described theoretically using a model based on the Poisson-NernstPlanck equations together with the geometrical and electrical single pore characteristics.

\section{Materials and methods}

\subsection{Chemicals and materials}

All the chemicals, including sodium hydroxide and potassium chloride, ammonium chloride, tetramethylammonium chloride, tetraethylammonium chloride and tetrabutylammonium chloride were purchased from Sigma-Aldrich, Schnelldorf, Germany, and used without further purification. 


\subsection{Fabrication of single asymmetric nanopores}

The nanopores were fabricated using the asymmetric track-etching technique developed by Apel and co-workers [38]. The first step was the irradiation of $12 \mu \mathrm{m}$ thick polyethylene terephthalate (PET) membranes (Hostaphan RN 12, Hoechst) with swift heavy ions (Au) of kinetic energy 11.4 MeV/nucleon at the linear accelerator UNILAC (GSI Helmholtz Centre for Heavy Ion Research, Darmstadt, Germany). Secondly, the latent ion tracks created by the swift heavy ion in the polymer membranes were sensitized with soft UV light. Finally, the chemical track-etching process was performed in a custom-made conductivity cell having three chambers. This conductivity cell was employed for the fabrication of the single-pore. To this end, a singleshot ( 1 ion hitting the foil) membrane was placed in the conductivity cell and clamped tightly. An etching solution $(9 \mathrm{M} \mathrm{NaOH})$ was filled on one side, while on the other side of the membrane a stopping solution $(1 \mathrm{M} \mathrm{KCl}+1 \mathrm{M} \mathrm{HCOOH})$ was filled in the adjoining compartment of the conductivity cell. To monitor the etching process, gold electrodes were inserted on both sides of the single-ion irradiated membrane and a potential of $-1 \mathrm{~V}$ was applied across the membrane. The etching process was carried out at room temperature. The current remained zero as long as the etchant had not permeated the whole length of the membrane. After the breakthrough (a point at which the etchant pierced the membrane), an increase in the ionic current flowing through the nascent pore was observed. The etching process was stopped when the current reached a certain defined value. Then, the membranes were thoroughly washed with stopping solution in order to neutralize the etchant, followed by deionized water. The etched membranes were dipped in deionized water overnight in order to remove the residual salts. This process resulted in polymer samples containing approximately conical single pores with carboxylic groups (-COOH) generated on the inner pore walls due to the hydrolysis of ester bonds in the back-bone of polymer chains. 


\subsection{Current-voltage (I-V) measurements}

The $I-V$ curves were measured using a picoammeter/voltage source (Keithley 6487, Keithley Instruments, Cleveland, Ohio, USA) and LabVIEW 6.1 (National Instruments) software. The as-prepared single-pore membrane was fixed between the two compartments of the conductivity cell and an aqueous electrolyte was filled in both halves of this cell. The electrodes consisted of $\mathrm{Ag}$ wires coated with $\mathrm{AgCl}$ and were inserted into each half-cell solution to fix the transmembrane potential giving the ionic current through the pore. The ground and working electrodes were placed on the base and tip side, respectively. In order to record the $I-V$ curves, a scanning triangle voltage signal from -2 to $+2 \mathrm{~V}$ was used.

\subsection{Model simulations}

The experimental $I-V$ curves were analyzed in terms of a model based on the PoissonNernst-Planck (PNP) equations [24-27]. Assuming a conical shape for the pore, the input parameters of the model were the diffusion coefficients of the ionic species, the surface concentration of the fixed charges on the pore surface, $\sigma$, and the diameters of the base, $D$, and tip, $d$, of the pore. As a first approximation, the diffusion coefficients corresponding to an aqueous solution at low electrolyte concentration were used in the calculations (see Table 1 and References $[39,40])$. The pore base diameter was determined directly from the etching time [38] and the pore tip diameter was calculated by fitting the $I-V$ curves measured at $100 \mathrm{mM} \mathrm{KCl}$ and $\mathrm{pH}=3.5$ to the theoretical model. In this case, the pore fixed groups were protonated $(\sigma=0)$ and the only unknown model parameter was $d$. Once the pore diameters were determined, the surface concentration $\sigma$ of fixed charges was calculated by fitting the $I-V$ curves to the theory in each experimental case. Hence, the only free parameter of the model is the effective charge density $\sigma$. 


\section{Results and discussion}

The ionization state of carboxylic acid groups on the pore surface regulates the permselectivity, conduction, and rectification characteristics of the pore [10]. Under physiological conditions, the as-prepared conical pore transports preferentially cations over anions due to the negative charge of the carboxylate groups, resulting in nonlinear $I-V$ curves [2, 10-14]. The nanopore surface and ionic transport characteristics can be regulated by the solution $\mathrm{pH}$ and the concentrations of $\mathrm{A}^{+}, \mathrm{TMA}^{+}, \mathrm{TEA}^{+}$, and $\mathrm{TBA}^{+}$cations in water. Fig. 1(A) and (B) shows ionic transport through the single nanopore for the different cations at neutral $(\mathrm{pH} 6.5)$ and acidic ( $\mathrm{pH}$ 3.5) conditions. Moreover, chemical structures of the cations used in this study are also shown in Fig. 1(C).

Fig. 2(A) shows the experimental $I-V$ characteristics at close to physiological conditions (pH 6.5) and organic cation concentrations ranging from 50 to $500 \mathrm{mM}$. The measurements were performed under symmetric solution conditions and the electrolyte solutions were prepared in 10 $\mathrm{mM}$ Tris-buffer. The working electrode is fixed on the cone tip side, serving as a cathode for positive bias and an anode for reversed bias. In this electrode configuration, high currents were recorded at positive voltages while low currents were obtained at negative voltages. The pore exhibits current rectification (cations preferentially flow from the tip opening towards the base opening) due to the existence of ionized carboxylate $\left(\mathrm{COO}^{-}\right)$groups which impart negative charge to the pore surface $[2,10-14]$. As expected, the rectification decreases with the ionic concentration [10]. The pore rectification behavior can be quantified by the rectification ratio $\left(f_{\text {rec }}\right)$. This ratio is obtained by dividing the absolute value of the forward current to that of reverse current at voltages of the same amplitude but opposite polarities, e.g. $f_{\text {rec }}=|I(+2 \mathrm{~V})| /|I(-2 \mathrm{~V})|$. Fig. 2(C) shows the values of $f_{\text {rec }}$ obtained from the corresponding $I-V$ curves. 
The experimental $I-V$ curves of Fig. 2(A) show similar conduction characteristics for the $\mathrm{K}^{+}$ and $\mathrm{A}^{+}$cations because of their almost identical ionic conductivities and diffusion coefficients. For all the organic cations employed, $\mathrm{A}^{+}$exhibits the highest rectified ion current. The replacement of the hydrogen atoms attached to the central nitrogen atom with alkyl (methyl, ethyl and butyl) groups leads to a substantial reduction of the ion current. The highest current corresponds to $\mathrm{TMA}^{+}$because of its relatively small size and decreased hydrophobic characteristics compared with those of $\mathrm{TEA}^{+}$and $\mathrm{TBA}^{+}$[41]. For the $100 \mathrm{mM}$ case, the $\mathrm{TBA}^{+}$ and $\mathrm{TEA}^{+}$currents are 1.1 and $1.9 \mathrm{nA}$ at $+2 \mathrm{~V}$, respectively, to be compared with $2.8 \mathrm{nA}$ for $\mathrm{TMA}^{+}$. Fig. 2 shows also the significant effect of the organic cation concentration on the absolute currents and rectifications. As expected, the rectification decreases with the concentration and follows the decreasing order $\mathrm{TMA}^{+}>\mathrm{TEA}^{+}>\mathrm{TBA}^{+}$in all experiments.

The continuous curves of Fig. 2(B) correspond to model calculations with the experimental diffusion coefficients of Table 1 . The conical pore parameters $d=24 \mathrm{~nm}$ and $D=370 \mathrm{~nm}$ are obtained using the experiments with $\mathrm{K}^{+}$at concentration $100 \mathrm{mM}$ and $\mathrm{pH} 3.5$, according to the procedure described in section 2.4. Table 2 shows the effective surface charge densities obtained. The model results follow qualitatively the experimental trends observed and, in particular, reproduce the sequence $\mathrm{K}^{+} \approx \mathrm{A}^{+}>\mathrm{TMA}^{+}>\mathrm{TEA}^{+}>\mathrm{TBA}^{+}$of the electric currents measured at positive voltages. The $\sigma$ values obtained at $\mathrm{pH} 6.5$ (Table 2) suggest a decrease of the effective surface charge due to the adsorption of the hydrophobic organic cations on the pore surface. The agreement between theory and experiments is excellent for the cases of $\mathrm{K}^{+}$and $\mathrm{A}^{+}$at concentrations above $100 \mathrm{mM}$ but becomes worse for the organic ions, especially in the case of $\mathrm{TBA}^{+}$. The deviations between the theoretical results and the experimental data should be attributed to additional effects not included in the model such as the particular hydrophobic characteristics of each organic ion and the concentration dependence of the ionic diffusion 
coefficients. In addition, deviations from the assumed conical geometry [2, 10-14] and uniform distribution $\sigma$ of the surface charge [2,10-14] could also be possible. We have preferred to concentrate on qualitative aspects only and have not attempted a more detailed modeling $[12,13]$ with additional parameters.

Fig. 3 shows the concentration dependence of the nanopore conductance measured at $+2 \mathrm{~V}$ for the different cations. The slope obtained for the concentration-dependence of the conductance decreases in the order $\mathrm{A}^{+}>\mathrm{TMA}^{+}>\mathrm{TEA}^{+}>\mathrm{TBA}^{+}$, which should be attributed to the effects of cation size and solvation, as well as to the partial adsorption of the positively charged hydrophobic ions on the negatively charged pore surface. Note also that the cation hydrophobicity increases with the alkyl chain, thus decreasing the ionic conductivity. This experimental trend has also been found experimentally and theoretically in free aqueous solutions [42]

Fig. 4(A) shows the $I-V$ curves obtained at different concentrations under acidic conditions (pH 3.5). Below pH 3.8 approximately, the carboxylic acid groups are protonated and the net charge on the pore walls is zero. For the uncharged conical pores, no current rectification should then be observed. However, the experimental data suggests an inversion of the current rectification characteristics with respect to Fig. 2 at low concentrations (50 and $100 \mathrm{mM})$. This inversion could be attributed again to the partial adsorption of the hydrophobic cations on the neutral pore surface, in agreement with the case of $\mathrm{pH} 6.5$ in Fig. 2. This adsorption is still possible because of the hydrophobic interaction between the alkyl chains and the polymeric chains of this surface. The final result is that the pore preferably transports anions over cations in this case. Because of the reversed sign of the pore charges, the rectification ratio is now defined as $f_{\text {rec }}=|I(-2 \mathrm{~V})| /|I(+2 \mathrm{~V})|$ and can be obtained from the $I-V$ curves of Fig. 4(A). For the case of the non-alkylated cations $\left(\mathrm{K}^{+}\right.$and $\left.\mathrm{A}^{+}\right) f_{\text {rec }}$ is close to 1 , while for the other organic cations it is 
close 2 as shown in Fig. 4(C). Shao and co-workers have also found that glass nanopipettes exposed to low concentrations of tetraphenylarsonium tetraphenylborate (TPAsTPB) show an inversion in the current rectification characteristics because of the adsorption of bulky cations $\left(\mathrm{TPAs}^{+}\right)$on the pore surface [23]. As expected, the current rectification decreases at high concentrations (250 and $500 \mathrm{mM}$ ) and the nanopore exhibits a quasi-ohmic behavior.

The theoretical results of Fig. 4(B) have been obtained with the same diffusion coefficients and pore diameters used for the case of $\mathrm{pH} 6.5$ in Fig. 2(B). The effective surface charge densities are shown in Table 2 . The model results qualitatively describe the experimental trends. In particular, an inversion of the current rectification characteristics with respect to the case of Fig. 2 is clearly observed at low concentrations. This fact is consistent with the adsorption of the hydrophobic cations on the pore walls, leading to the positive surface charge concentrations of Table 2 .

We have also checked the reproducibility of the ionic conduction data for different nanopores. Fig. 5(A) shows the $I-V$ curves obtained with a conical pore with similar tip and base diameters at concentration $100 \mathrm{mM}$. For $\mathrm{pH}$ 6.5, the pore exhibits experimental trends similar to those of Fig. 2. However, an inversion in the current rectification is observed under acidic conditions, thus confirming the effect observed in Fig. 4. The rectification rations obtained for this case is calculated from the corresponding $I-V$ curves is also shown in Fig. 5(C). The theoretical curves of Fig. 5(B) have been obtained using the same procedure as in Figs. 2 and 4. In this case, the pore diameters are $d=21 \mathrm{~nm}$ and $D=390 \mathrm{~nm}$ and the $\sigma$ values are given in Table 3. These model parameters are similar to those obtained for the pore sample of Figs. 2-4 and permit also an approximate theoretical description of the experimental trends observed.

\section{Conclusions}


Biomimetic nanopores provide new opportunities for electrochemically-based sensing. However, most published studies concern the case of inorganic salts despite the increasing importance of organic cations. We have described previously the $\mathrm{pH}$-dependent electrodiffusion of amino acids through fixed-charge membranes [43] and Au-nanotubule membranes with selfassembled monolayers [44]. We consider now the ionic conduction of different $\mathrm{TAA}^{+}$cations through a nanofluidic diode fabricated in a polymer membrane via asymmetric track-etching techniques. Aqueous solutions of ammonium, tetramethylammonium, tetraethylammonium, and tetrabutylammonium ions are used over a wide concentration range under different $\mathrm{pH}$ conditions. The increase of the cation hydrophobicity with the alkyl chain gives low rectified ion currents for $\mathrm{TMA}^{+}, \mathrm{TEA}^{+}$, and $\mathrm{TBA}^{+}$compared with those of $\mathrm{K}^{+}$and $\mathrm{A}^{+}$. The inversion of the current rectification characteristics observed at low concentrations and acidic conditions is attributed to the adsorption of the organic cations on the pore walls. The experimental results can be approximately described in terms of the Poisson-Nernst-Planck equations and the geometrical and electrical single pore characteristics for the different ions, $\mathrm{pH}$ values, and salt concentrations employed. In this way, the only free parameter of the model is the effective charge density $\sigma$. This theoretical approach is qualitative and could be extended to include a self-consistent theoretical treatment of the ionic adsorption and surface charge equilibria.

\section{Acknowledgements}

M. A., S. N., and W.E. acknowledge the funding from the Hessen State Ministry of Higher Education, Research and the Arts, Germany, under the LOEWE project iNAPO. P. R., J. C., and S. M. acknowledge financial support by the Spanish Ministry of Economic Affairs and Competitiveness (MAT2015-65011-P) and FEDER. The authors are also thankful to Prof. C. 
Trautmann, Department of Materials Research from GSI, for support with irradiation experiments. 


\section{References}

[1] B. Hille, Ionic channels of excitable membranes, 3rd ed., Sinauer Associates Inc., Sunderland, MA, 2001.

[2] M. Ali, P. Ramirez, S. Mafe, R. Neumann, W. Ensinger, A pH-Tunable Nanofluidic Diode with a Broad Range of Rectifying Properties, ACS Nano, 3 (2009) 603-608.

[3] C. Dekker, Solid-state nanopores, Nat. Nanotechnol., 2 (2007) 209-215.

[4] R.E. Gyurcsanyi, Chemically-modified nanopores for sensing, Trends Anal. Chem., 27 (2008) 627-639.

[5] K. Healy, B. Schiedt, A.P. Morrison, Solid-state nanopore technologies for nanopore-based DNA analysis, Nanomedicine, 2 (2007) 875-897.

[6] J.J. Kasianowicz, J.W.F. Robertson, E.R. Chan, J.E. Reiner, V.M. Stanford, Nanoscopic porous sensors, Ann. Rev. Anal. Chem., 1 (2008) 737-766.

[7] Z.S. Siwy, S. Howorka, Engineered voltage-responsive nanopores, Chem. Soc. Rev., 39 (2010) 11151132.

[8] R. Spohr, Status of ion track technology - Prospects of single tracks, Radiat. Meas., 40 (2005) 191-202.

[9] X. Hou, W. Guo, L. Jiang, Biomimetic smart nanopores and nanochannels, Chem. Soc. Rev., 40 (2011) 2385-2401.

[10] J. Cervera, B. Schiedt, R. Neumann, S. Mafe, P. Ramirez, Ionic Conduction, Rectification, and Selectivity in Single Conical Nanopores, J. Chem. Phys., 124 (2006) 104706.

[11] J. Cervera, B. Schiedt, P. Ramirez, A Poisson/Nernst-Planck model for ionic transport through synthetic conical nanopores, Europhys. Lett., 71 (2005) 35-41.

[12] P. Ramirez, P.Y. Apel, J. Cervera, S. Mafe, Pore Structure and Function of Synthetic Nanopores with Fixed Charges: Tip Shape and Rectification Properties, Nanotechnology, 19 (2008) 315707.

[13] P. Ramirez, V. Gomez, J. Cervera, B. Schiedt, S. Mafe, lon transport and selectivity in nanopores with spatially inhomogeneous fixed charge distributions, J. Chem. Phys., 126 (2007) 194703.

[14] Z.S. Siwy, lon-Current Rectification in Nanopores and Nanotubes with Broken Symmetry, Adv. Funct. Mater., 16 (2006) 735-746.

[15] M. Ali, S. Nasir, I. Ahmed, L. Fruk, W. Ensinger, Tuning nanopore surface polarity and rectification properties through enzymatic hydrolysis inside nanoconfined geometries, Chem. Commun., 49 (2013) 8770-8772.

[16] S. Nasir, M. Ali, P. Ramirez, V. Gómez, B. Oschmann, F. Muench, M. Nawaz Tahir, R. Zentel, S. Mafe, W. Ensinger, Fabrication of Single Cylindrical Au-Coated Nanopores with Non-Homogeneous Fixed Charge Distribution Exhibiting High Current Rectifications, ACS Appl. Mater. Interfaces, 6 (2014) 1248612494.

[17] R. Karnik, C.H. Duan, K. Castelino, H. Daiguji, A. Majumdar, Rectification of ionic current in a nanofluidic diode, Nano Lett., 7 (2007) 547-551.

[18] I. Vlassiouk, Z.S. Siwy, Nanofluidic Diode, Nano Lett., 7 (2007) 552-556.

[19] R. Yan, W. Liang, R. Fan, P. Yang, Nanofluidic Diodes Based on Nanotube Heterojunctions, Nano Lett., 9 (2009) 3820-3825.

[20] M. Davenport, A. Rodriguez, K.J. Shea, Z.S. Siwy, Squeezing lonic Liquids through Nanopores, Nano Lett., 9 (2009) 2125-2128.

[21] T. Plett, W. Shi, Y. Zeng, W. Mann, I. Vlassiouk, L.A. Baker, Z.S. Siwy, Rectification of nanopores in aprotic solvents - transport properties of nanopores with surface dipoles, Nanoscale, 7 (2015) 1908019091.

[22] T.S. Plett, W. Cai, M. Le Thai, I.V. Vlassiouk, R.M. Penner, Z.S. Siwy, Solid-State Ionic Diodes Demonstrated in Conical Nanopores, J. Phys. Chem. C, 121 (2017) 6170-6176. 
[23] X. Yin, S. Zhang, Y. Dong, S. Liu, J. Gu, Y. Chen, X. Zhang, X. Zhang, Y. Shao, lonic Current Rectification in Organic Solutions with Quartz Nanopipettes, Anal. Chem., 87 (2015) 9070-9077.

[24] W.I. Babiaczyk, S. Bonella, L. Guidoni, G. Ciccotti, Hydration Structure of the Quaternary Ammonium Cations, J. Phys. Chem. B, 114 (2010) 15018-15028.

[25] C.M. Starks, Phase-transfer catalysis. I. Heterogeneous reactions involving anion transfer by quaternary ammonium and phosphonium salts, J. Am. Chem. Soc., 93 (1971) 195-199.

[26] G. Merle, M. Wessling, K. Nijmeijer, Anion exchange membranes for alkaline fuel cells: A review, J. Membr. Sci., 377 (2011) 1-35.

[27] R. MacKinnon, G. Yellen, Mutations affecting TEA blockade and ion permeation in voltage-activated K+ channels, Science, 250 (1990) 276-279.

[28] C.M. Armstrong, L. Binstock, Anomalous Rectification in the Squid Giant Axon Injected with Tetraethylammonium Chloride, J. Gen. Physiol., 48 (1965) 859-872.

[29] B. Hille, The selective inhibition of delayed potassium currents in nerve by tetraethylammonium ion, J. Gen. Physiol., 50 (1967) 1287-1302.

[30] R. Coronado, C. Miller, Conduction and block by organic cations in a K+-selective channel from sarcoplasmic reticulum incorporated into planar phospholipid bilayers, J. Gen. Physiol., 79 (1982) 529547.

[31] C.J. Huang, I. Favre, E. Moczydlowski, Permeation of large tetra-alkylammonium cations through mutant and wild-type voltage-gated sodium channels as revealed by relief of block at high voltage, J. Gen. Physiol., 115 (2000) 435-454.

[32] A. Tinker, A.R. Lindsay, A.J. Williams, Large tetraalkyl ammonium cations produce a reduced conductance state in the sheep cardiac sarcoplasmic reticulum $\mathrm{Ca}(2+)$-release channel, Biophys. J., 61 (1992) 1122-1132.

[33] T. Malinski, D. Chang, F.N. Feldmann, J.L. Bear, K.M. Kadish, Electrochemical studies of a novel ruthenium(II, III) dimer, trifluoroacetamidatoruthenium chloride (Ru2(HNOCCF3)4Cl), Inorg. Chem., 22 (1983) 3225-3233.

[34] G. De Murcia, B. Wilhelm, F.X. Wilhelm, M.P. Daune, Effect of tetramethylammonium ions on conformational changes of DNA in the premelting temperature range, Biophys. Chem., 8 (1978) 377-383. [35] W.I. Wood, J. Gitschier, L.A. Lasky, R.M. Lawn, Base composition-independent hybridization in tetramethylammonium chloride: a method for oligonucleotide screening of highly complex gene libraries, Proc. Natl. Acad. Sci. USA, 82 (1985) 1585-1588.

[36] Y. Wang, F. Yao, X.-f. Kang, Tetramethylammonium-Filled Protein Nanopore for Single-Molecule Analysis, Anal. Chem., 87 (2015) 9991-9997.

[37] Y. Wang, Y. Zhang, Y. Guo, X.-f. Kang, Fast and precise detection of DNA methylation with tetramethylammonium-filled nanopore, Sci. Rep., 7 (2017) 183.

[38] P.Y. Apel, Y.E. Korchev, Z. Siwy, R. Spohr, M. Yoshida, Diode-Like Single-lon Track Membrane Prepared by Electro-Stopping, Nucl. Instrum. Methods Phys. Res., Sect. B, 184 (2001) 337-346.

[39] J. Buffle, Z. Zhang, K. Startchev, Metal Flux and Dynamic Speciation at (Bio)interfaces. Part I: Critical Evaluation and Compilation of Physicochemical Parameters for Complexes with Simple Ligands and Fulvic/Humic Substances, Environ. Sci. Technol., 41 (2007) 7609-7620.

[40] R. Ishimatsu, J. Kim, P. Jing, C.C. Striemer, D.Z. Fang, P.M. Fauchet, J.L. McGrath, S. Amemiya, IonSelective Permeability of an Ultrathin Nanoporous Silicon Membrane as Probed by Scanning Electrochemical Microscopy Using Micropipet-Supported ITIES Tips, Anal. Chem., 82 (2010) 7127-7134. [41] Y. Koga, P. Westh, K. Nishikawa, S. Subramanian, Is a Methyl Group Always Hydrophobic? Hydrophilicity of Trimethylamine-N-oxide, Tetramethyl Urea and Tetramethylammonium Ion, J. Phys. Chem. B, 115 (2011) 2995-3002.

[42] H.N. Sarode, G.E. Lindberg, Y. Yang, L.E. Felberg, G.A. Voth, A.M. Herring, Insights into the Transport of Aqueous Quaternary Ammonium Cations: A Combined Experimental and Computational Study, J. Phys. Chem. B, 118 (2014) 1363-1372. 
[43] M. Minagawa, A. Tanioka, P. Ramirez, S. Mafe, Amino acid transport through cation exchange membranes: Effects of pH on interfacial transport, J. Colloid Interface Sci., 188 (1997) 176-182.

[44] J.R. Ku, S.M. Lai, N. Ileri, P. Ramirez, S. Mafe, P. Stroeve, pH and ionic strength effects on amino acid transport through Au-nanotubule membranes charged with self-assembled monolayers, J. Phys. Chem. C, 111 (2007) 2965-2973.

[45] T. Jimbo, P. Ramirez, A. Tanioka, S. Mafe, N. Minoura, Passive Transport of lonic Drugs through Membranes with pH-Dependent Fixed Charges, J. Colloid Interface Sci. 225 (2000) 447-454. 


\section{Figures and Captions}


Fig. 1. (A) Scheme of the size and hydrophobic-based cation conduction through a negatively charged conical nanopore (pH 6.5) for $V>0$. (B) Scheme showing the pore charge reversal at acidic conditions $(\mathrm{pH} 3.5)$ due to adsorption of alkyl cations and the concomitant anion conduction across the membrane for $V<0$. (C) Chemical structures of the cations employed in this study. 

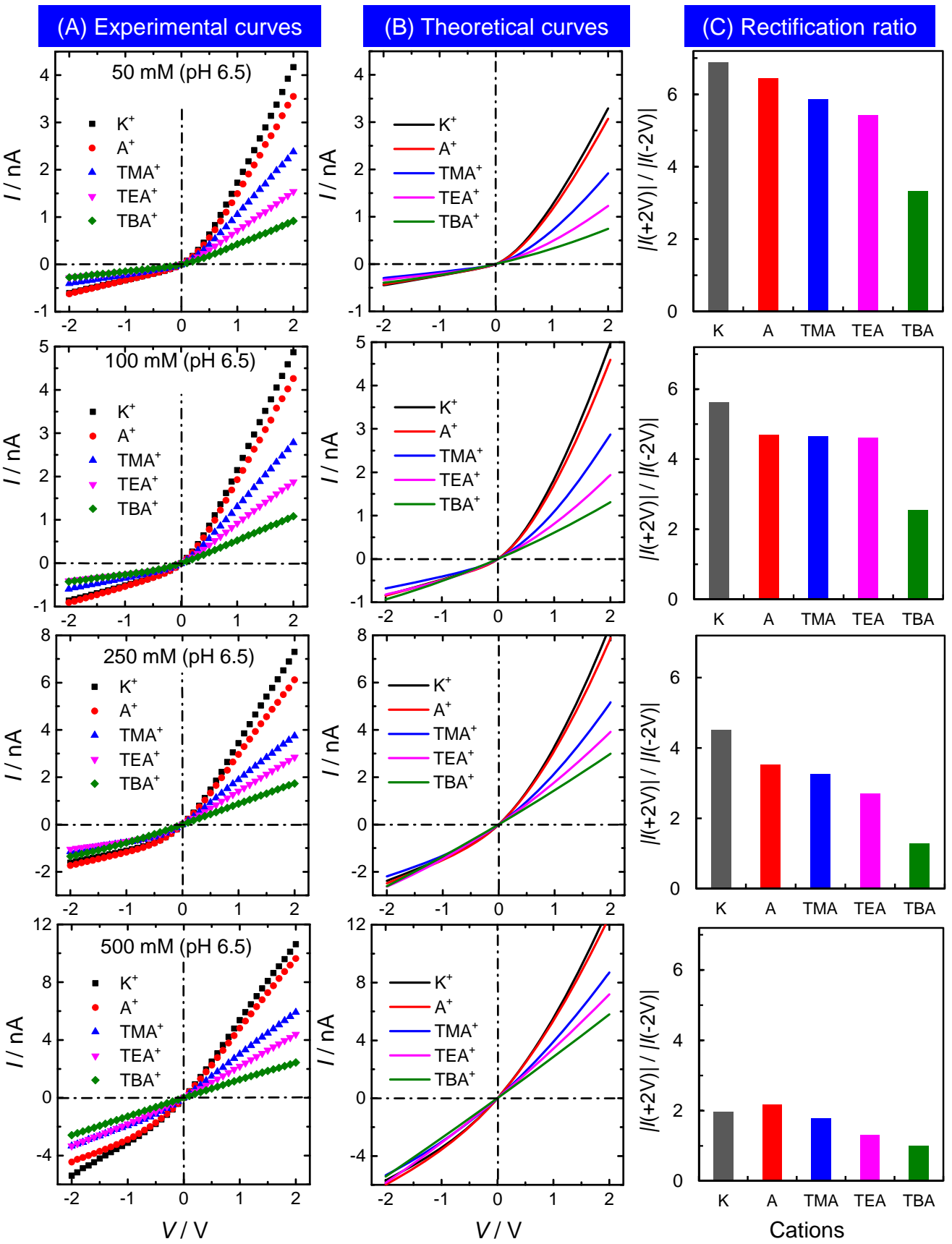

Fig. 2. (A) Experimental $I-V$ curves of a single conical nanopore $(d=24 \mathrm{~nm}, D=370 \mathrm{~nm})$ with negatively charged carboxylate groups $(\mathrm{pH} 6.5)$ for potassium $\left(\mathrm{K}^{+}\right)$, ammonium $\left(\mathrm{A}^{+}\right)$, tetramethylammonium $\left(\mathrm{TMA}^{+}\right)$, tetraethylammonium $\left(\mathrm{TEA}^{+}\right)$and tetrabutylammonium $\left(\mathrm{TBA}^{+}\right)$cations at the concentrations $50,100,250$ and $500 \mathrm{mM}$. (B) Theoretical $I-V$ curves corresponding to the experimental data assuming the diffusion coefficients of Table 1 and the surface charge concentrations of Table 2. (C) Typical rectification ratios obtained from the corresponding $I-V$ curves at $2 \mathrm{~V}$. 


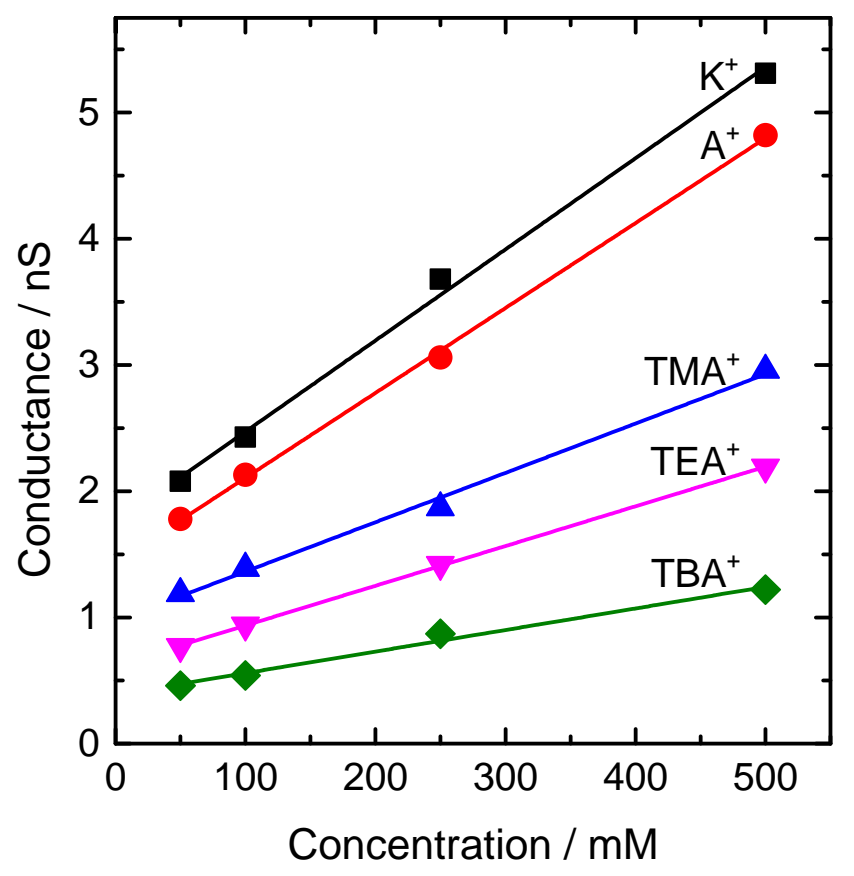

Fig. 3. Pore conductance as a function of the concentration for the experimental data of Fig. 2 at $+2 \mathrm{~V}$. 


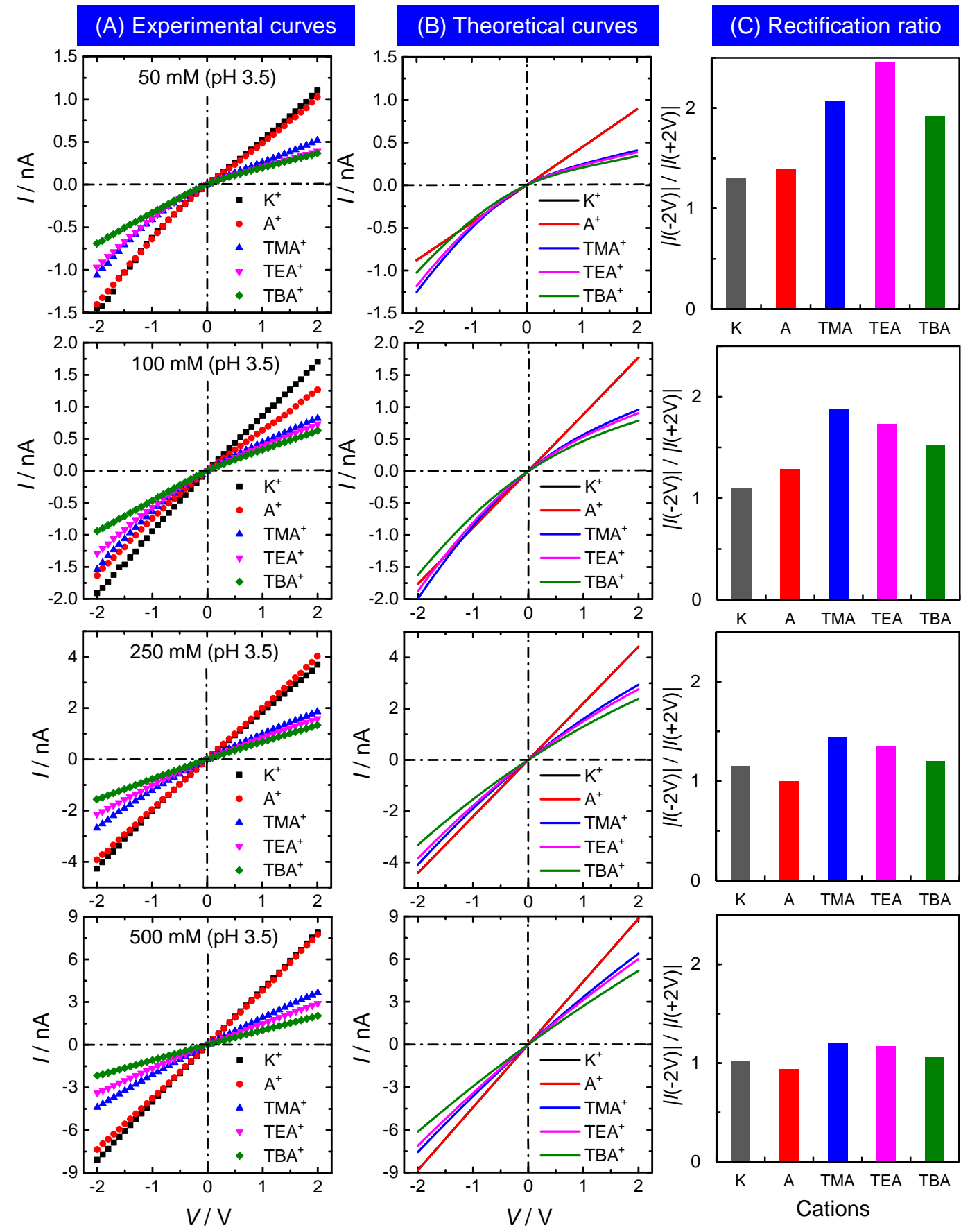

Fig. 4. (A) Experimental $I-V$ curves of a single conical nanopore $(d=24 \mathrm{~nm}, D=370 \mathrm{~nm})$ with uncharged carboxylic acid groups (pH 3.5) for the cations of Fig. 2 at the concentrations 50, 100, 250 and $500 \mathrm{mM}$. (B) Theoretical $I-V$ curves corresponding to the experimental data assuming the diffusion coefficients of Table 1 and the surface charge concentrations of Table 2. (C) Typical rectification ratios obtained from the corresponding $I-V$ curves at $2 \mathrm{~V}$. 


\section{(A) Experimental curves}

\section{(B) Theoretical curves}


Fig. 5. (A) Experimental $I-V$ curves of a single conical nanopore $(d=21 \mathrm{~nm}, D=390 \mathrm{~nm})$ with negatively charged $(\mathrm{pH}$ 6.5) and uncharged ( $\mathrm{pH} \mathrm{3.5)} \mathrm{carboxylic} \mathrm{acid} \mathrm{groups} \mathrm{in} 100 \mathrm{mM}$ solutions of the cations of Fig. 2. (B) Theoretical $I-V$ curves corresponding to the experimental data assuming the diffusion coefficients of Table 1 and the surface charge concentrations of Table 3. (C) Typical rectification ratios obtained from the corresponding $I-V$ curves at $2 \mathrm{~V}$. 


\begin{tabular}{|c|c|c|c|c|c|}
\hline \multicolumn{6}{|c|}{$D_{i}\left(10^{-5} \mathrm{~cm}^{2} / \mathrm{s}\right)$} \\
\hline $\mathrm{Cl}^{-}$ & $\mathrm{K}^{+}$ & $\mathrm{A}^{+}$ & $\mathrm{TMA}^{+}$ & $\mathrm{TEA}^{+}$ & $\mathrm{TBA}^{+}$ \\
\hline 2.03 & 1.95 & 1.95 & 1.1 & 0.91 & 0.5 \\
\hline
\end{tabular}

Table 1. The diffusion coefficients of the ionic species used in the model calculations correspond to the experimental values obtained for free electrolyte solutions $[39,40]$. 


\begin{tabular}{|c|c|c|c|c|c|}
\hline & \multicolumn{5}{|c|}{$\sigma\left(e / \mathrm{nm}^{2}\right)$} \\
\hline $\mathrm{pH}$ & $\mathrm{K}^{+}$ & $\mathrm{A}^{+}$ & $\mathrm{TMA}^{+}$ & $\mathrm{TEA}^{+}$ & $\mathrm{TBA}^{+}$ \\
\hline 6.5 & -0.3 & -0.25 & -0.15 & -0.06 & -0.02 \\
\hline 3.5 & 0 & 0 & 0.05 & 0.05 & 0.05 \\
\hline
\end{tabular}

Table 2. Surface charge concentrations used in the model calculations of Figs. 2 (pH 6.5) and 4 (pH 3.5). 


\begin{tabular}{|c|c|c|c|c|c|}
\hline & \multicolumn{5}{|c|}{$\sigma\left(e / \mathrm{nm}^{2}\right)$} \\
\hline $\mathrm{pH}$ & $\mathrm{K}^{+}$ & $\mathrm{A}^{+}$ & $\mathrm{TMA}^{+}$ & $\mathrm{TEA}^{+}$ & $\mathrm{TBA}^{+}$ \\
\hline 6.5 & -0.2 & -0.17 & -0.1 & -0.07 & -0.03 \\
\hline 3.5 & 0 & +0.01 & +0.02 & +0.05 & +0.1 \\
\hline
\end{tabular}

Table 3. Surface charge concentrations used in the model calculations of Fig. 5. 